\title{
Proteína degradável no rúmen e frequência de suplementação para novilhos Nelore em pastejo: Desempenho produtivo e análise econômica
}

\section{Rumen degradable protein and frequency of supplementation for Nellore steers grazing: performance and economic analysis}

\author{
Leonardo Vaz de Figueiredo Assad ${ }^{1 *}$; Joanis Tilemahos Zervoudakis ${ }^{2}$; \\ Luciano da Silva $\mathrm{Cabral}^{2}$; Luciana Keiko Hatamoto-Zervoudakis ${ }^{2}$; \\ Pedro Veiga Rodrigues Paulino²; Eduardo Henrique Bevitori Kling de Moraes $^{2}$; \\ Renata Pereira da Silva-Marques ${ }^{3}$; Jefferson Fabiano Werner Koscheck ${ }^{4}$
}

\begin{abstract}
Resumo
Avaliaram-se o efeito da proteína degradável no rúmen (PDR) e da frequência de suplementação sobre o ganho de peso médio diário, peso corporal final e viabilidade econômica de bovinos em pastagem de Brachiaria brizantha cv. Marandu durante o período de transição águas-seca. Foram utilizados 25 novilhos Nelore com peso corporal médio inicial de 287,96 $\pm 7,47 \mathrm{~kg}$ e idade média inicial de 18 meses, distribuídos em cinco piquetes de 1,6 ha cada. O delineamento foi inteiramente casualizado com cinco suplementos e cinco repetições. Foram avaliados os seguintes suplementos: SAL - mistura mineral fornecida ad libitum (Controle); PDR diário - suplemento formulado para atendimento das exigências em PDR, com fornecimento diário; PDR freqüência - suplemento formulado para atendimento das exigências em PDR fornecido três vezes por semana (segundas, quartas e sextas-feiras); PDR+ - suplemento formulado com acréscimo de 10\% nas exigências em PDR fornecido 3X; PDR- - suplemento formulado com 10\% a menos da exigência em PDR fornecido 3X. Os animais suplementados apresentaram ganho de peso médio diário (GMD) superior ( $\mathrm{P}=0,0010)$ ao suplemento controle. Os suplementos PDR diário e PDR frequência não apresentaram diferença significativa $(\mathrm{P}>0,05)$ para o GMD. Houve diferença significativa do GMD do suplemento PDR frequência $(\mathrm{P}=0,0189)$ em relação ao suplemento PDR -. Na avaliação econômica, observou retorno econômico positivo para os suplementos: PDR frequência, PDR diário, PDR + e PDR-. A estratégia de fornecimento de suplemento PDR frequência proporcionou o melhor retorno econômico. A suplementação em dia alternado para novilhos em pastejo proporciona maior ganho de peso corporal final e maior GMD, os quais são efetivos em promover rentabilidade econômica e desempenho produtivo maiores aos obtidos em sistemas a pasto com fornecimento diário de suplemento. Palavras-chave: Brachiaria brizantha, forragem, ganho médio diário, suplemento múltiplo
\end{abstract}

\footnotetext{
Abstract

It was aimed at to evaluate the effect of the degradable protein in the rumen (RDP) and the supplementation frequency on the average daily gain weight, final body weight and economic viability of cattle in pasture

${ }^{1}$ M.e em Ciência Animal, Universidade Federal de Mato Grosso, UFMT, Cuiabá, MT. E-mail: leo.assad@gmail.com

2 Profs. Drs., UFMT, Cuiabá, MT. E-mail: joanis@ufmt.br; cabralls@ufmt.br; lukeiko@yahoo.com.br; pedro_paulino@cargill. com; edukling@ufmt.br

3 Discente de Doutorado em Ciência Animal, UFMT, Cuiabá, MT. E-mail: renatinharps@hotmail.com

${ }^{4}$ Discente de Doutorado em Zootecnia, Universidade Estadual Paulista, UNESP, Jaboticabal, SP. E-mail: jeffersonfwk@hotmail.com

* Autor para correspondência
} 
of Brachiaria brizantha $\mathrm{cv}$. Marandu during the rainy/dry transition period. 25 Nellore steers withinitial body weight of $287.96 \pm 7.47 \mathrm{~kg}$ and average initial age of 18 months, distributed into eight paddocks of 1.6 ha each, were used. The experimental design was completely randomized with five replicates and five supplements. The supplements were: SAL - mineral mix supplied ad libitum (Controls); daily RDP: supplement formulated to meet the requirements RDP, with daily supply; frequency RDP: supplement formulated to meet the requirements RDP, supplied three times on week (Mondays, Wednesdays and Fridays); RDP+: supplement formulated with increment of $10 \%$ of the requirements of RDP supplied 3X; RDP-: supplement formulated with less $10 \%$ of the requirements of RDP supplied $3 \mathrm{X}$. The supplemented animals showed average daily gain $(A D G)$ greater $(P=0.0010)$ to control supplement. The RDP daily supplements and RDP frequency showed no significant difference $(\mathrm{P}>0.05)$ for the GMD. There was a significant difference in ADG of frequency RDP $(P=0.0189)$ compared to the RDP- supplement. In the economic evaluation revealed positive economic return to the supplements: frequency RDP, daily RDP, RDP + and RDP-. The strategy of supplying the frequency RDP supplement provided the best economic return. Supplementation in alternate day for grazing steers provides greater gain final and higher body weight ADG, which are effective in promoting economic profitability and higher growth performance to those obtained in the pasture systems daily supply of supplement.

Key words: Brachiaria brizantha, forage, average daily gain, multiple supplement

\section{Introdução}

A produção brasileira de carne é um importante elo do agronegócio. O crescente aumento da população mundial acarreta em aumento exacerbado da demanda por produtos de origem animal, o qual tem gerado novas oportunidades para o setor produtivo. No entanto, têm surgido novos desafios, principalmente quanto à necessidade de aumento na eficiência de produção de forma sustentável (DE PAULA et al., 2014).

A eficiência no sistema produtivo de bovinos de corte é amplamente influenciada pela produtividade e qualidade das gramíneas tropicais, as quais sofrem variação sazonal alo longo do ano,devido às condições climáticas, não permitindo ganho de peso constante dos animais, acarretando em baixos índices zootécnicos (PAULINO et al., 2004).

No períodofinal das águas e início da seca (período de transição águas-seca) a forragem rapidamente tem redução do teor de proteína bruta e aumento do teor de fibra indigerível, o que acarreta em limitação do seu consumo e, desta forma, o atendimento das necessidades nutricionais dos animais (REIS et al., 2005). Neste contexto, é necessário o fornecimento de suplemento concentrado com adição de proteína degradável no rúmen (PDR) para potencializar o crescimento microbiano do rúmen, essencial para maximizar o consumo e digestibilidade da forragem (BERCHIELLI; VEGA-GARCIA; OLIVEIRA, 2011).

A determinação da composição do suplemento é fator importante em um programa de suplementação, pois auxilia na estimativa do ganho de peso dos animais e na definição do custo total com suplemento. Além disso, outro fator de destaque é o custo com a distribuição diária dos suplementos. Neste contexto, a redução na frequência de distribuição dos suplementos é uma estratégia de suplementação que tem sido avaliada com o intuito de permitir ao produtor uma oportunidade de redução no tempo, mão-de-obra e equipamentos associados com a suplementação, permitindo desta forma, reduzir custos e aumentar a lucratividade do sistema (DE PAULA et al., 2010).

Objetivou-se avaliar diferentes suprimentos de proteína degradável no rúmen em suplementos múltiplos distribuídos de forma distinta quanto à frequência de fornecimento, bem como sobre o ganho de peso médio diário, peso corporal final e viabilidade econômica de novilhos Nelore em pastagem de Brachiaria brizantha cv. Marandu durante o período de transição águas-seca. 


\section{Material e Métodos}

O experimento foi conduzido no setor de Bovinocultura de Corte da Fazenda Experimental da Universidade Federal de Mato Grosso, localizada no município de Santo Antônio do Leverger - Mato

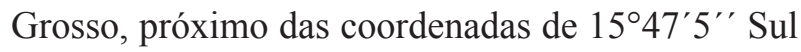
e $56^{\circ} 04^{\prime}$ Oeste, com altitude de 140 metros, durante o período de transição águas-seca do ano, entre os meses de março e junho.

Foram utilizados 25 novilhos Nelore, não castrados, com idade e peso médio inicial de aproximadamente 18 meses e $287,96 \pm 7,47 \mathrm{~kg}$, respectivamente. A área experimental destinada aos animais de desempenho foi constituída de cinco piquetes de 1,6 ha cada, cobertos uniformemente com Brachiaria brizanha cv. Marandu, providos de bebedouros e cochos cobertos para fornecimento do suplemento, com área de cocho suficiente para acesso de todos os animais simultaneamente. A área experimental permaneceu vedada entre os meses de novembro a abril.

Foram avaliados cinco suplementos experimentais, sendo: Suplemento Controle (Mistura mineral fornecida ad libitum); Suplementos formulados para atendimento das exigências de proteína degradável no rúmen (PDR) e nutrientes digestíveis totais (NDT) de bovinos zebuínos machos, não castrados, com peso corporal de $300 \mathrm{~kg}$, para ganho de peso de $1,0 \mathrm{~kg} / \mathrm{dia}$ de acordo com Valadares Filho, Paulino e Magalhães (2006), com fornecimento diário- PDR diário e com fornecimento com frequência reduzida - PDR frequência (segundas, quartas e sextasfeiras);Suplemento formulado com acréscimo de $10 \%$ das exigências de proteína degradável no rúmen (PDR) com fornecimento com frequência reduzida (segundas, quartas e sextas - feiras)PDR + ;Suplemento formulado com $10 \%$ a menos da exigência de PDR, com fornecimento com frequência reduzida (segundas, quartas e sextas feiras)- PDR- (Tabela 1).

Tabela 1. Composição dos suplementos ( $\mathrm{g} / \mathrm{kg}$ de matéria natural) e valores de proteína bruta e nutrientes digestíveis totais $(\mathrm{g} / \mathrm{kg}$ de matéria seca).

\begin{tabular}{|c|c|c|c|c|}
\hline \multirow{2}{*}{ Ingredientes } & \multicolumn{4}{|c|}{ Suplementos } \\
\hline & PDR & $\mathrm{PDR}+$ & PDR - & SAL \\
\hline Farelo de soja & 250,0 & 340,0 & 95,0 & $\begin{array}{ll}---- \\
-\cdots\end{array}$ \\
\hline Milho Grão Moído & 635,0 & 535,0 & 795,0 & ----- \\
\hline Ureia/Sulfato de amônia (9:1) & 15,0 & 25,0 & 10,0 & ----- \\
\hline \multirow[t]{2}{*}{ Mistura Mineral $^{1}$} & 100,0 & 100,0 & 100,0 & 1000,0 \\
\hline & \multicolumn{4}{|c|}{ Composição (g/kg de MS) } \\
\hline PB & 230,1 & 291,2 & 138,9 & \\
\hline NDT & 880,3 & 872,7 & 887,3 & \\
\hline
\end{tabular}

${ }^{1}$ Mistura mineral comercial - Níveis de garantia: cálcio $198 \mathrm{~g}$; fósforo $60 \mathrm{~g}$; sódio $117 \mathrm{~g}$; magnésio 5,1g; enxofre 12,6g; iodo 17,7mg; ferro 425mg; selênio 10,4mg; cobalto $80 \mathrm{mg}$; manganês $527 \mathrm{mg}$; flúor $600 \mathrm{mg}$; cobre $1.000 \mathrm{mg}$ e zinco $3.000 \mathrm{mg}$

Fonte: Elaboração dos autores.

Os suplementos foram fornecidos em quantidades equivalentes a $1 \mathrm{~kg} / \mathrm{animal} / \mathrm{dia}$, em duas frequências semanais (diariamente e três vezes por semana), às 10:00 horas. Os animais suplementados com frequência reduzida três vezes por semana (segundas, quartas e sextas-feiras) receberam a mesma quantidade semanal de suplementos que os animais suplementados diariamente. 
Os animais foram pesados no início e final do experimento após serem submetidos a jejum de sólidos de 14 horas. Após a pesagem inicial os animais foram estratificados com base no peso corporal (PC) e distribuídos em cinco lotes aleatoriamente. Os animais foram pesados cada 28 dias sem jejum e sempre pela manhã, para monitoramento do ganho de peso. Antes do início do experimento, todos os animais foram submetidos ao controle de endo e ectoparasitas.

Visando minimizar a influência da possível variação na disponibilidade da massa de forragem entre os piquetes, foi realizado o rodízio dos animais a cada sete dias (mantendo-se o fornecimento dos mesmos suplementos aos animais) entre os piquetes.

Foram realizadas coletas de amostras dos suplementos e ingredientes utilizados durante o preparo das misturas para as análises laboratoriais. No primeiro dia de cada período experimental foram coletada amostras de forragem nos diferentes piquetes, através do corte, a $5 \mathrm{~cm}$ do solo, de 5 áreas delimitadas por um quadrado metálico de $0,5 \times 0,5$ $\mathrm{m}$, escolhidos aleatoriamente para a determinação da massa de forragem seca total (MFST) e massa de forragem seca potencialmente digestível (MFSpD).

Após a coleta, as amostras de cada piquete foram pesadas e homogeneizadas, e a partir dessas forma retiradas duas alíquotas compostas: uma para avaliação da MFST/ha e outra para fracionamento dos componentes estruturais da planta e posterior análise das disponibilidades por hectare de MS de folha verde, folha seca, colmo verde e colmo seco. A amostragem da forragem consumida pelos animais foi obtida via simulação manual do pastejo, realizada no inicio de cada período experimental.

Das amostras destinadas à estimativa da MFST, foi determinado o resíduo insolúvel em detergente neutro avaliado após incubação in situ das amostras por 240 horas (CASALI et al., 2008), para cálculo do percentual de MS potencialmente digestível (MFSpD) disponível aos animais. Esse resultado foi estimado por intermédio da seguinte equação:
$\mathrm{MFSpD}=0,98 \mathrm{X}(100-\mathrm{FDN})+(\mathrm{FDN}-\mathrm{FDNi}) ; \mathrm{em}$ que $0,98=$ coeficiente de digestibilidade verdadeiro do conteúdocelular; FDNi $=$ FDN indigestível.

As determinações da MS, matéria orgânica $(\mathrm{MO})$, proteína bruta $(\mathrm{PB})$, fibra em detergente neutro (FDN), fibra em detergente ácido (FDA), fibra em detergente neutro corrigida para cinza e proteína (FDNcp), lignina, extrato etéreo (EE) e matéria mineral (MM), foi realizada de acordo com descrições de Silva e Queiroz (2002). A determinação do nitrogênio insolúvel em detergente neutro (NIDN) e ácido (NIDA) foram realizadas de acordo com os métodos descritos por Licitra, Hernandez e van Soest (1996).

A quantificação dos carboidratos não fibrosos (CNF) dos suplementos foi realizada de acordo com adaptação de Hall (2000) em virtude da inclusão de ureia na composição dos suplementos, sendo:

$\mathrm{CNF}=100-[(\% \mathrm{~PB}-\% \mathrm{~PB}$ da ureia $+\%$ ureia $)+$ FDNcp $+\%$ EE $+\%$ cinzas]; onde: FDNcp $=$ fibra em detergente neutro corrigida para cinza e proteína.

Os teores de nutrientes digestíveis totais (NDT) e os teores de proteína degradável no rúmen (PDR) foram estimados de acordo com recomendações do NRC (2001), através da seguinte equação: PDR = $\mathrm{A}+\mathrm{B} *(\mathrm{Kd} / \mathrm{Kd}+\mathrm{Kp})$; em que: $\mathrm{A}$ - corresponde a fração solúvel em água; B - fração insolúvel em água e potencialmente degradável; $\mathrm{Kd}$ - taxa de degradação da fração B e Kp - taxa de passagem da $\mathrm{PB}$ pelo rúmen. Os valores de A (\%), B (\%) e Kd $(\% / h)$ dos ingredientes utilizados, foram obtidos de Valadares Filho, Rocha Júnior e Capelle (2002) e o valor do Kp utilizado foi de $5 \% / \mathrm{h}$.

A avaliação econômica foi realizada tendo em vista os custos com os suplementos e a receita obtida. Foi considerado rendimento de carcaça de $52 \%$. O custo com suplementos foi obtido através da multiplicação do consumo de suplemento/anima/ dia pelo valor do $\mathrm{kg}$ de suplemento; o custo com distribuição de suplementos foi obtido pelo tempo necessário para distribuição de todos os suplementos (30 minutos) dividido pelo número de tratamentos 
(5) e pelo número de animais (5) e multiplicados pela hora homem + hora máquina $(\mathrm{R} \$ 30,00)$ e pelo número de dias de suplementação (PDR diário e sal =7 dias na semana; PDR freq. , PDR+ e PDR= 3 dias na semana); o custo total foi obtido pela soma dos custos de suplementação e distribuição de suplementos; o ganho em equivalente de carcaça foi obtido pela multiplicação do ganho de peso corporal dos animais em 84 dias pelo rendimento de carcaça e divido pela@ (15 kg); o ganho total em @/há foi obtido pela multiplicação do ganho em equivalente carcaça pelo número de animais e dividido pela área experimental (1,6 ha); o custo por arroba produzida foi obtido pela divisão do custo total pelo ganho em equivalente de carcaça; o ganho de peso corporal adicional (PCA) foi obtido pelo ganho diferencial em relação ao animais do suplemento mineral; a receita $(\mathrm{RC})$ por $\mathrm{kg}$ de PCA foi obtida pelo rendimento de carcaça de $52 \%$ e preço da arroba (15 kg) da região de $\mathrm{R} \$ 78,00$; o retorno do PCA foi obtido pela multiplicação da RC pelo PCA e por 84 dias; a resposta produtiva foi obtida pela divisão do PCA pelo consumo de suplemento; o preço máximo do kg de suplemento (PMS) foi obtido pela multiplicação da RC pela resposta produtiva; o custo máximo da suplementação/animal/dia foi obtido pela multiplicação do consumo de suplemento pelo PMS; e o retorno econômico foi obtido pela divisão do retorno do PCA/custos da suplementação. Todas as cotações empregadas foram tomadas no Estado de Mato Grosso e no período em que se conduziu este experimento.

O experimento foi analisado segundo delineamento inteiramente casualizado. Os procedimentos estatísticos foram realizados por intermédio do programa SAS (2008), adotando-se 0,05 como nível crítico de probabilidade. Para a variável ganho médio diário utilizou-se a análise de covariância utilizando-se o peso vivo inicial (PVI) como co-variável do GPT e GMD, segundo técnica descrita por Snedecor e Cochran (1989), como o PVI não foi significante, o modelo foi refeito deslocando-se os graus de liberdade a ele atribuído para o resíduo. Caso houvesse efeito de tratamento pela ANOVA os contrastes ortogonais foram utilizados para partição específica dos efeitos de tratamento, comparando-se SAL versus PDR diário, PDR diário versus PDR frequência, $\mathrm{PDR}+$ versus PDR frequência e PDR- versus PDR frequência.

\section{Resultados e Discussão}

A massa de forragem seca total (MFST) média, massa de forragem seca potencialmente digestível (MFSpD), massa de folha verde (MFV), massa de folha seca (MFS), massa de colmo verde (MCV) e massa de colmo seco (MCS) da Brachiaria brizantha cv. Marandu em função dos períodos experimentais apresentaram valores médios de 6102; 4600; 1815; $573 ; 3460$ e $254 \mathrm{~kg} / \mathrm{ha}$, respectivamente (Figura 1).

Durante todos os períodos experimentais, os valores médios de MFST encontraram-se bem acima dos valores considerados críticos de 2000 $\mathrm{kg} / \mathrm{ha}$. No início do terceiro período experimental apresentou o menor valor de MFST (5726 kg de $\mathrm{MS} /$ há). Este valor é 1,72 vezes superior ao valor mínimo de 4. 500kg de MS total ha-1 preconizados por Silva et al. (2009) para garantir seletividade e ganhos individuais satisfatórios sem comprometer o ganho por área.

Já a disponibilidade de MFSpD média durante o período experimental foi superior $(52,7 \mathrm{~g} / \mathrm{kg}$ de peso corporal de MFSpD) ao valor recomendado por Paulino et al. (2004) de 4 a $5 \mathrm{~g} / \mathrm{kg}$ de peso corporal de MFSpD de forragem para que se proporcione equilíbrio entre a produção por animal e a produção por área, proporcionando aumento na eficiência de uso da forragem.

A biomassa disponível de forragem durante todos os períodos experimentais favoreceu o pastejo seletivo, possivelmente possibilitando a maximização do consumo de MS. Nos resultados referentes à disponibilidade de MS das frações componentes da forragem, observou-se que a participação da folha verde na massa de forragem 
reduziu $22,8 \%$ do início para o final do experimento, passando de $2692 \mathrm{~kg} / \mathrm{ha}$ para $1084 \mathrm{~kg} / \mathrm{ha}$. Isto deve ter sido resultado, principalmente, do pastejo seletivo exercido pelos animais e de diminuição da taxa de crescimento da forrageira devido ao déficit hídrico observado ao final do experimento.

Figura 1. Valores médios em $\mathrm{kg}$ /ha para massa de forragem seca total (MFST) média, massa de forragem seca potencialmente digestível (MFSpD), massa de folha verde (MFV), massa de folha seca (MFS), massa de colmo verde (MCV) e massa de colmo seco (MCS) da Brachiaria brizantha cv. Marandu em função dos períodos experimentais.

\section{صPERÍODO 1 田PERÍODO 2 图PERÍODO 3}

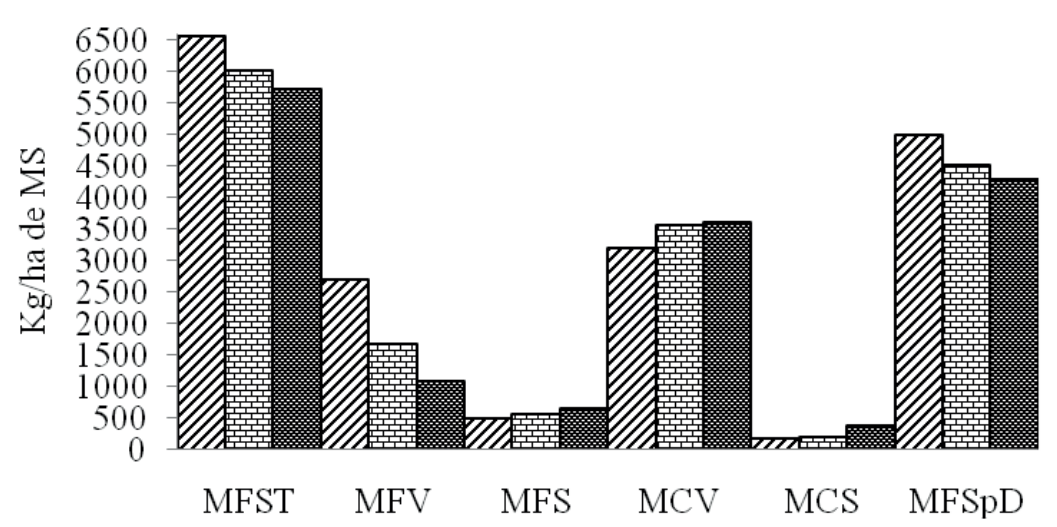

Fonte: Elaboração dos autores.

Segundo Moraes et al. (2010), quando ocorre longo período de ocupação das pastagens, há redução na disponibilidade de forragem e mudanças na estrutura morfológica das plantas, principalmente na proporção folha/colmo, que podem afetar de forma severa, o consumo de forragem e, consequentemente a produção animal. No entanto, isso pode não ocorrer dependendo da taxa de lotação ou pressão de pastejo e época do ano.

De acordo com Reis et al. (1997), as gramíneas tropicais devido a sua elevada taxa de crescimento, possui alterações morfológicas intensas, como aumento na proporção de colmo e diminuição na proporção de folha. Em virtude disso, ocorre redução no seu valor nutritivo, uma vez que à medida que a idade fisiológica avança ocorre lignificação da parede celular, reduzindo a proporção de conteúdo celular, notadamente nos colmos.
O teor médio de PB das amostras obtidas pelo pastejo simulado durante o período experimental foi de 80,9 $\mathrm{g} / \mathrm{kg}$ de MS (Tabela 2). De acordo com Detmann et al. (2009), o crescimento dos microrganismos ruminais é comprometido quando as concentrações de nitrogênio amoniacal ruminal são inferiores a $8 \mathrm{mg} / \mathrm{dL}$ de liquido ruminal. Sendo assim, o valor médio de PB apresentado pela forragem durante todo o experimento não foi fator limitante para o crescimento microbiano, e consequentemente para a utilização da fração potencialmente degradável da fibra em detergente neutro.

Adicionalmente, foram verificados elevados teores de FDN, FDA e lignina (Tabela 2), resultante da elevada taxa de crescimento da forrageira no período de vedação. Nas três características químicobromatológicas, os maiores valores obtidos foram no primeiro período experimental, que apresentou valores médios de 769,6; 333,0; e 38,2 g/kg de MS de FDN, FDA e lignina, respectivamente. 
Tabela 2. Composição nutricional dos suplementos e da forragem.

\begin{tabular}{|c|c|c|c|c|}
\hline \multirow{2}{*}{ Item } & \multicolumn{3}{|c|}{ Suplementos } & \multirow{2}{*}{ Brachiaria brizantha } \\
\hline & PDR * & $\mathrm{PDR}+* *$ & PDR -*** & \\
\hline $\mathrm{MS}^{1}$ & 886,6 & 886,6 & 871,9 & 359,3 \\
\hline $\mathrm{MO}^{2}$ & 915,6 & 912,7 & 920,7 & 926,3 \\
\hline $\mathrm{PB}^{2}$ & 230,1 & 291,2 & 138,9 & 80,9 \\
\hline $\mathrm{PDR}^{3 ; 4}$ & 645,8 & 681,3 & 610,5 & ----- \\
\hline $\mathrm{NIDN}^{3}$ & 47,6 & 40,3 & 89,1 & 461,0 \\
\hline $\mathrm{NIDA}^{3}$ & 30,6 & 26,9 & 35,6 & 394,0 \\
\hline $\mathrm{EE}^{2}$ & 37,8 & 34,0 & 39,3 & 29,2 \\
\hline $\mathrm{CZ}^{2}$ & 84,4 & 87,3 & 79,3 & 73,7 \\
\hline $\mathrm{FDN}^{2}$ & 147,1 & 146,2 & 146,7 & 752,5 \\
\hline $\mathrm{FDNcp}^{2}$ & 130,6 & 129,8 & 130,3 & 694,3 \\
\hline $\mathrm{FDNi}^{2}$ & 65,9 & 65,7 & 66,4 & 241,3 \\
\hline FDA $^{2}$ & 100,7 & 104,7 & 89,4 & 324,7 \\
\hline $\mathrm{CNF}^{2}$ & 544,3 & 503,0 & 630,3 & 121,9 \\
\hline Lignina $^{2}$ & 13,1 & 14,1 & 11,7 & 33,0 \\
\hline NDT & 880,3 & 872,7 & 887,3 & ----- \\
\hline
\end{tabular}

${ }^{1} \mathrm{~g} / \mathrm{kg}$ de matéria natural; ${ }^{2} \mathrm{~g} / \mathrm{kg}$ de matéria seca ${ }^{3} \mathrm{~g} / \mathrm{kg}$ de Nitrogênio total; ${ }^{4}$ Estimado segundo o NRC (2001); ${ }^{*}$ PDR: Suplemento formulado para atendimento das exigências de proteína degradável no rúmen de acordo com Valadares Filho, Paulino e Magalhães (2006); **PDR +: Suplemento formulado com acréscimo de 10\% das exigências de proteína degradável no rúmen; ***PDR -: Suplemento formulado com $10 \%$ a menos da exigência de proteína degradável no rúmen.

Fonte: Elaboração dos autores.

Os animais do suplemento controle de transição águas-seca, quando comparado apresentaram consumo médio de sal mineral de com animais que recebem apenas mistura 0,074 kg/animal/dia e os animais dos suplementos mineral (VILLELA et al., 2009; MORAES et PDR diário, PDR freq., PDR+ e PDR- consumiram $1 \mathrm{~kg}$ de suplemento/animal/dia, correspondendo a $0,29 \%$ do peso corporal médio. De acordo com Silva et al. (2009) em revisão sobre suplementação durante a época seca, este nível de suplementação $(<0,3 \%$ PC) quando utilizado acarretou em "efeito aditivo", ou seja,aumentou o consumo de forragem e consequentemente o ganho de peso animal.

Neste contexto, verifica-se que a suplementação com alterou o GMD (Tabela 3), uma vez que os animais que receberam suplementos múltiplos com PDR diariamente apresentaram maior GMD $(\mathrm{P}=0,0010)$ em relação aos animais do suplemento controle (MM). Diversos autores observaram ganhos adicionais para os animais que recebem suplementação múltipla ou proteica no período al., 2006; BARBOSA et al., 2007). Além disso, a suplementação múltipla promoveu elevação no GMD de até $260 \mathrm{~g} / \mathrm{dia}(22,60 \%)$ quando comparado ao grupo controle.

O ganho adicional pode ser justificado pela afirmação feita por Kabeya et al. (2002), de que à medida que a proporção de forragem seca ou senescente aumenta na pastagem durante o fim da estação de crescimento, os animais tornamse mais seletivos e o consumo pode ser reduzido. Quando oportunidades para pastejo seletivos são reduzidas, maior quantidade de forragem madura (com menores teores de nutrientes e digestibilidade) seria ingerida e os consumos de nutrientes e energia adicionalmente reduzidos; como consequência os níveis de ganho são menores. Sendo assim, ao observar os ganhos adicionais pode se afirmar que 
a suplementação múltipla com PDR foi efetiva em melhorar a digestibilidade da forragem consumida, consequentemente, melhorando o consumo total de MS e de energia digestível.

Tabela 3. Consumo de suplemento (CS), peso corporal inicial (PCI), peso corporal final (PCF), ganho médio diário (GMD) e contrastes ortogonais em função dos suplementos Mistura Mineral, PDR diário, PDR frequência, PDR +, PDR -

\begin{tabular}{|c|c|c|c|c|c|c|c|c|c|c|}
\hline \multirow{2}{*}{ Variáveis } & \multicolumn{5}{|c|}{ Suplementos } & \multirow{2}{*}{ CV $(\%)$} & \multicolumn{4}{|c|}{ Contraste $^{2}$} \\
\hline & $\mathrm{MM}^{1}$ & PDR diário & PDR freq. & PDR + & PDR - & & SPDR & FREQ & $\mathrm{PF}+$ & PF- \\
\hline CS (kg/dia) & 0,074 & 1,0 & 1,0 & 1,0 & 1,0 & & & & & \\
\hline PCI (kg) & 254,5 & 292,4 & 293,7 & 304,3 & 294,9 & 12,98 & - & - & - & - \\
\hline PCF (kg) & 329,1 & 386,64 & 390,2 & 400 & 378,2 & 11,35 & 0,0254 & 0,8840 & 0,6828 & 0,6225 \\
\hline GMD (kg) & 0,89 & 1,12 & 1,15 & 1,14 & 0,99 & 12,93 & 0,0010 & 0,6710 & 0,8846 & 0,0189 \\
\hline
\end{tabular}

${ }^{1}$ Mistura mineral; ${ }^{2 /}$ SPDR $=$ SAL versus PDR diário; FREQ $=$ PDR diário versus PDR frequência; $\mathrm{PF}+=$ PDR frequência versus PDR +;PF- = PDR frequência versus PDR -

Fonte: Elaboração dos autores.

Em relação aos suplementos com mesma formulação, porém diferenciados pela estratégia de fornecimento (PDR diário e PDR frequência). Estes não apresentaram diferença significativa $(\mathrm{P}>0,05)$. Desta forma, constatou-se que o fornecimento de suplementos múltiplos no período de transição águas-seca em menor frequência (3X/semana), constitui alternativa viável para redução dos custos envolvidos no processo de suplementação, racionalização da mão de obra e equipamentos, sem, contudo afetar o desempenho produtivo dos animais (Tabela 3 ).

Em consonância com estes resultados, Goes et al. (2005) e Moraes et al. (2006) não verificaram diferenças estatísticas no ganho de peso de novilhos suplementados com diferentes frequências de suplementação (diária, duas vezes por semana e três vezes por semana). Com base nisso, estes autores relataram que a redução na frequência de distribuição de suplementos para três vezes por semana, não prejudicou o desempenho dos animais.

O fornecimento de suplementos três vezes por semana apresenta eficiência na utilização de nitrogênio semelhante à suplementação diária, em bovinos consumindo forragens de qualidade inferior (BOHNERT; SCHAUER; DELCURTO, 2002), podendo, assim, as diferentes frequências de fornecimento não influenciarem o desempenho dos animais.

Os ruminantes apresentam a capacidade de sustentar elevados teores de amônia ruminal nos intervalos entre os dias suplementados, podendo favorecer o processo digestivo e a conservação do $\mathrm{N}$. O mecanismo para tal fato pode ser explicado pela capacidade dos ruminantes em reciclar nitrogênio e manter a digestão da fibra nos intervalos entre suplementações, semelhantes aos verificados nos animais que recebem suplementação diária, e pela capacidade de manutenção dos níveis de nitrogênio entre os intervalos de suplementação devido à alteração na permeabilidade do trato gastrintestinal a componentes da dieta (ex. ureia), e ou então à regulação da excreção de ureia pelo animal (BOHNERT; SCHAUER; DELCURTO, 2002).

Outra hipótese para os semelhantes ganhos de peso entre as diferentes frequências de suplementação foi levantada por Farmer et al. (2004), em que estes autores observaram uma 
relação positiva entre maior proporção molar de propionato, menor de acetato e menor relação acetato:propionato com a infrequência de suplementação, principalmente durante o período de 24 horas após a suplementação. Esta prolongada melhoria na relação acetato: propionato pode contribuir para a manutenção de satisfatório desempenho de bovinos de corte, quando o consumo de forragem é levemente reduzido com a menor frequência de suplementação.

A ausência de diferença estatística $(P>0,05)$ entre os suplementos PDR frequência e PDR + pode ser devido ao excesso de proteína na dieta que possivelmente elevou as concentrações de amônia no rúmen, acarretando em não aproveitamento pelo metabolismo microbiano/ animal. Se não aproveitado, o nitrogênio pode ser perdido por via urinária na forma de ureia, gerando balanço negativo de 1 ATP para cada molécula de ureia formada, o que pode acarretar, no caso de excesso, em perda energética, prejudicando o desempenho animal. Por outro lado, em alguns casos, embora a energia requerida para síntese de ureia não represente elevada proporção da energia digestível total ingerida, o fato da perda energética ser concentrado quase que exclusivamente sobre o fígado, pode causar competição por ATP com a via gliconeogênica do propionato. Depressões nas concentrações hepáticas de NADH, NADP e NADPH são relacionadas à elevação do nível hepático de amônia e síntese de ureia sob excesso proteico dietético, o que gera distúrbios sobre o metabolismo intermediário dos carboidratos (CHALUPA et al., 1970).

O suplemento PDR frequência apresentou maior GMD ( $\mathrm{P}=0,0189)$ em comparação ao suplemento PDR -(Tabela 4). Além disso, verifica-se ganho adicional de peso de $160 \mathrm{~g} /$ dia/animal para o PDR frequência. Este resultado demonstra que
10\% a menos de PDR foi suficiente para limitar o GMD. Sendo assim, é importante ressaltar que apesar do menor aporte de proteína suplementar e, consequente menor quantidade de substrato para o crescimento microbiano, o ganho de peso obtido de $0,99 \mathrm{~kg} /$ dia foi suficiente para alcançar o objetivo pré-determinado quando procedeu se à formulação do suplemento, mostrando que os animais foram capazes de reciclar o nitrogênio endógeno suprindo as necessidades dos microrganismos ruminais por compostos nitrogenados.

Segundo Mathis et al. (2000), bovinos consumindo forragem de baixa qualidade (baixo teor de PB e elevado teor de FDN) possuem melhor eficiência microbiana pois apresentam maior reciclagem de $\mathrm{N}$, um importante fator que deve ser considerado, contribuindo para o "pool" de N degradado no rúmen, razão pela qual, a quantidade de PDR consumida para alcançar o máximo consumo de forragem e digestibilidade é de 8 a $13 \%$ do total de matéria orgânica digestível.

Adicionalmente, verifica-se que não houve diferença significativa $(\mathrm{P}>0,05)$ do peso corporal final (PCF) nas comparações PDR diário vs. PDR freq., PDR freq. vs. PDR+ e PDR freq. vs. PDR- No entanto, pode-se observar que os animais do suplemento PDR diário apresentaram maior $(\mathrm{P}=0,0254) \mathrm{PCF}$ em relação aos animais do sal mineral, ou seja, a suplementação com fornecimento diário possibilitou incremento de $57,54 \mathrm{~kg}$ ou 3,84 arrobas por animal, e consequentemente maiores ganho em arroba produzida por hectare(Tabela 4). Esses ganhos são imprescindíveis em sistemas onde se almeja abater animais mais jovens, tendo em vista que, há um aumento na rentabilidade, no giro de capital e menor emissão de metano, uma vez que, há desocupação de área para outras categorias e menor produção de metano por $\mathrm{kg}$ de carne produzida. 
Tabela 4. Indicadores econômicos de produção por animal para os diferentes suplementos.

\begin{tabular}{|c|c|c|c|c|c|}
\hline \multirow{2}{*}{ Indicadores Econômicos } & \multicolumn{5}{|c|}{ Suplementos } \\
\hline & $\mathrm{MM}^{1}$ & PDR diário & PDR freq. & PDR + & PDR - \\
\hline Consumo de Suplemento (kg/animal/dia) & 0,074 & 1,0 & 1,0 & 1,0 & 1,0 \\
\hline Custos dos suplementos $(\mathrm{R} \$ / \mathrm{kg})$ & 1,46 & 0,53 & 0,53 & 0,59 & 0,45 \\
\hline Custos dos suplementos $(\mathrm{R} \$ / \mathrm{dia})^{2}$ & 0,108 & 0,530 & 0,530 & 0,590 & 0,450 \\
\hline Custo da suplementação/animal (R \$/84 dias) & 9,08 & 44,52 & 44,52 & 49,56 & 37,80 \\
\hline Custo de distribuição do suplemento/animal $(\mathrm{R} \$)^{3}$ & 50,40 & 50,40 & 21,60 & 21,60 & 21,60 \\
\hline Custo Total $(\mathrm{R} \$)^{4}$ & 59,48 & 94,92 & 66,12 & 71,16 & 59,40 \\
\hline Peso corporal inicial $(\mathrm{kg})$ & 254,5 & 292,4 & 293,7 & 304,3 & 294,9 \\
\hline Peso corporal final $(\mathrm{kg})$ & 329,1 & 386,64 & 390,2 & 400 & 378,2 \\
\hline Ganho de peso corporal ( $\mathrm{kg} / 84$ dias $)$ & 74,6 & 94,24 & 96,5 & 95,7 & 83,3 \\
\hline Ganho de peso médio diário $(\mathrm{kg} / \mathrm{dia})$ & 0,888 & 1,122 & 1,149 & 1,139 & 0,992 \\
\hline Ganho de peso corporal ( $\mathrm{kg} / 84$ dias $)$ & 74,6 & 94,24 & 96,5 & 95,7 & 83,3 \\
\hline Ganho em equivalente rendimento de carcaça ${ }^{5}$ & 2,59 & 3,27 & 3,35 & 3,32 & 2,89 \\
\hline Ganho totalem @/ha ${ }^{6}$ & 8,08 & 10,21 & 10,45 & 10,37 & 9,02 \\
\hline Custo por arroba produzida $(\mathrm{R} \$)^{7}$ & 23,00 & 29,05 & 19,76 & 21,45 & 20,57 \\
\hline Peso corporal diário adicional $(\mathrm{PCA})(\mathrm{kg} / \mathrm{dia})^{8}$ & & 0,23 & 0,26 & 0,25 & 0,10 \\
\hline Receita $(\mathrm{R} \$)$ por kg de $\mathrm{PCA}^{9}$ & & 2,70 & 2,70 & 2,70 & 2,70 \\
\hline Retorno (R\$) do PCA em 84 dias $^{10}$ & & 53,11 & 59,22 & 57,05 & 23,52 \\
\hline Resposta produtiva (RP) $(\mathrm{kg} / \mathrm{kg})^{11}$ & & 0,23 & 0,26 & 0,25 & 0,10 \\
\hline Preço máximo do $\mathrm{kg}$ de suplemento $(\mathrm{PMS})(\mathrm{R} \$)^{12}$ & & 0,63 & 0,70 & 0,68 & 0,28 \\
\hline Custo máximo da suplementação/animal/dia $(\mathrm{R} \$)^{13}$ & & 0,63 & 0,70 & 0,68 & 0,28 \\
\hline Retorno econômico $(\mathrm{R} \$)^{14}$ & & 1,19 & 1,33 & 1,15 & 0,62 \\
\hline
\end{tabular}

${ }^{1}$ Mistura mineral; ${ }^{2}$ Consumo animal/dia* custo do suplemento; ${ }^{3}$ tempo necessário para distribuição de todos os suplementos $(0,5 \mathrm{~h}) /$ numero de tratamentos (5)/número de animais (5)* hora homem+hora máquina (R \$ 30,00)*numero de dias de suplementação(PDR diário e sal =7 dias na semana; PDR freq. , PDR+ e PDR- = 3 dias na semana), sendo = PDR diário e sal $(0,5 \mathrm{~h} / 5 / 5 * 30,00 * 84=50,40)$; PDR freq. , PDR+ e PDR- $(0,5 \mathrm{~h} / 5 / 5 * 30,00 * 36=21,60) ;{ }^{4}$ Custo da suplementação + distribuição de suplementos; ${ }^{5} \mathrm{Ganho}$ de peso corporal*52\% de rendimento de carcaça/@(15 kg); ${ }^{6}$ Equivalente carcaça*número de animais/área experimental (1,6 ha); ${ }^{7} \mathrm{Custo}$ total/Ganho em equivalente rendimento de carcaça; ${ }^{8} \mathrm{Ganho}$ diferencial em relação ao animais do suplemento mineral; ${ }^{9} \mathrm{Rendimento}$ de carcaça de $52 \%$ e preço da arroba $(15 \mathrm{~kg})$ de $\mathrm{R} \$ 78,00$, sendo $\mathrm{RC}=(78,00 / 15) * 0,52 ;{ }^{10} \mathrm{Retorno}=(\mathrm{RC} * \mathrm{PCA} * 84 \mathrm{dias}) ;{ }^{11} \mathrm{RP}=\mathrm{PCA} /$ consumo de suplemento; ${ }^{12}$ Receita*RP; ${ }^{13}$ (Consumo de suplemento*PMS); ${ }^{14}$ Retorno do PCA/custos da suplementação.

Fonte: Elaboração dos autores.

Com relação à análise econômica pode se verificar claramente a real importância dos custos totais de distribuição do suplemento (Tabela 4). O fornecimento do suplemento todos os dias da semana fez gerar despesas totais com o fornecimento do suplemento de $\mathrm{R} \$ 50,40$ por animal. Este valor correspondeu a $53,1 \%$ do custo total da estratégia de suplementação, colaborando com o maior custo total apresentado pelo suplemento. No entanto, quando se trabalhou com o fornecimento dos suplementos $3 \mathrm{X} /$ semana, os custos com distribuição foram reduzidos na ordem de 57\% ( $\mathrm{R} \$ 50,40$ vs $\mathrm{R} \$ 21,60)$ com relação ao fornecimento do suplemento diário.

Devido ao menor teor de PB e PDR do suplemento PDR -, houve uma redução na ordem de 15,09\% e $23,73 \%$ no custo/kg quando comparado com os suplementos formulados com objetivo de atender as exigências de PDR dos animais (PDR diário e/ ou frequência) e o suplemento PDR +. Entretanto, apesar do menor custo do suplemento PDR -, o menor GMD obtido acarretou em um menor retorno econômico (Tabela 4). 
Com relação ao suplemento PDR +, devido ao seu maior teor de PDR, houve um acréscimo de 11,32\% no custo/kg quando comparado com os suplementos PDR diário e PDR frequência. Entretanto, apesar da maior quantidade em PDR, o suplemento PDR + obteve ganhos de peso inferior ao do suplemento PDR frequência.

O suplemento PDR frequência, além de proporcionar numericamente o melhor GMD, teve a vantagem adicional de ter sido fornecido apenas três vezes por semana, o que resultou em menor custo total de suplementação com relação aos suplementos PDR diário e PDR +. Este menor custo total juntamente com o GMD obtido fez com que o suplemento obtivesse melhor retorno econômico (R\$ 1,33) quando comparados aos outros suplementos. Este valor foi R\$ 1,33; 0,14; 0,18 e 0,71 acima dos resultados obtidos com os suplementos Mistura Mineral (Controle), PDR diário, PDR+ e PDR-, respectivamente.

Todos os suplementos tiveram retorno econômico positivo. Apesar do suplemento PDR- ter apresentado menor ganho de peso médio diário, os custos totais com o fornecimento de $1 \mathrm{~kg} /$ dia deste suplemento foi de R \$ 0,45/dia, e o custo máximo permitido com esse suplemento acima do qual não se viabiliza a suplementação seria de R\$ 0,28/dia (Tabela 4). Logo, os ganhos de peso adicionais diários obtidos com esse suplemento foram capazes de abonar os custos diários da suplementação.

No entanto, esses indicadores não computam os benefícios com a antecipação da liberação das pastagens. Para Porto et al. (2009) a lucratividade da suplementação no período das águas não depende apenas da relação entre preço do insumo e arroba do boi, mas também do ganho em desocupação das pastagens.

\section{Conclusões}

O fornecimento de suplementos múltiplos para novilhos de corte no período transição águas-secas proporciona desempenho e retorno financeiro positivo. A estratégia de suplementação com fornecimento de suplemento (três vezes por semana) atendendo as exigências em PDR se destaca como a de melhor rentabilidade econômica.

\section{Referências}

BARBOSA, F. A.; GRAÇA, D. S.: MAFFEI, W. E.; SILVA JÚNIOR, F. V.; SOUZA, G. M. Desempenho e consumo de matéria seca de bovinos sob suplementação proteico energética, durante a época de transição águaseca. Arquivo Brasileiro de Medicina Veterinária e Zootecnia, Belo Horizonte, v. 59, n. 1, p. 160-167, 2007.

BERCHIELLI, T. T.; VEGA-GARCIA, A.; OLIVEIRA, S. G. Principais técnicas de avaliação aplicadas em estudo de nutrição. In: BERCHIELLI, T. T.; PIRES, A. V.; OLIVEIRA, S. G. (Ed.). Nutrição de ruminantes. 2. ed. Jaboticabal: Funep, 2011. p. 565-600.

BOHNERT, D. W.; SCHAUER, C. S.; DELCURTO, $\mathrm{T}$. Influence of rumen protein degradability and supplementation frequency on performance and nitrogen use in ruminants consuming low-quality forage: Cow performance and efficiency of nitrogen use in wethers. Journal of Animal Science, Champaign, v. 80, n. 6, p. 1629-1637, 2002.

CASALI, A. O.; DETMANN, E.; VALADARES FILHO, S. C.; PEREIRA, J. C.; HENRIQUES, L. T.; FREITAS, S. G.; PAULINO, M. F. Influencia do tempo de incubação e do tamanho de partículas sobre os teores de compostos indigestíveis em alimentos e fezes bovinas obtidos por procedimento in situ. Revista Brasileira de Zootecnia, Viçosa, MG, v. 37, n. 2, p. 335-342, 2008.

CHALUPA, W.; CLARK, J.; OPLIGER, P.; LAVKER, R. Detoxication of ammonia in sheep fed soy protein or urea. Journal of Nutrition, Rockville Pike, v. 100, n. 1, p. 170-176, 1970.

DE PAULA, N. F.; PAULINO, M. F.; COUTO, V. R. M.; DETMANN, E.; MACIEL, I. F. S.; VALENTE, É. E. L.; BARROS, L. V.; MENDES, R. K. V. Suplemento de baixo consumo para vacas de cortenão-gestantes. Semina: CiênciasAgrárias, Londrina, v. 35, n. 4, p. 1999 2010, 2014.

DE PAULA, N. F.; ZERVOUDAKIS, J. T.; CABRAL, L. C.; CARVALHO, D. M. G.; HATAMOTOZERVOUDAKIS, L. K.; MORAES, E. H. K.; OLIVEIRA, A. A. Frequência de suplementação e fontes de proteína para recria de bovinos em pastejo no período seco: desempenho produtivo e econômico. Revista 
Brasileira de Zootecnia, Viçosa, MG, v. 39, n. 4, p. 873$882,2010$.

DETMANN, E.; PAULINO, M. F.; MANTOVANI, H. C.; VALADARES FILHO, S. C.; SAMPAIO, C. B.; SOUZA, M. A.; LAZZARINI, I.; DETMANN, K. S. C. Parameterization of ruminal fibre degradation in lowquality tropical forage using Michaelis-Menten kinetics. Livestock Science, Almsford, v. 126, n. 1-3, p. 136-146, 2009.

FARMER, C. G.; COCHRAN, R. C.; NAGARAJA, T. G.; TITGEMEYER, E. C.; JOHNSON, D. E.; WICKERSHAM, T. A. Ruminal and host adaptations to change in frequency of protein supplementation. Journal of Animal Science, Champaign, v. 82, n. 3, p. 895-903, 2004.

GOES, R. H. T. B.; MANCIO, A. B.; ALVES, D. D.; LANA, R. P. Efeito da frequência da suplementação no desempenho de novilhos Nelore recriados em pasto de Brachiariabrizantha, na região Amazônica. Acta Scientiarum Animal Science, Maringá, v. 27, n. 4, p. 491496, 2005.

HALL, M. B. Calculation of non-structural carbohydrate content of feeds that contain non-protein nitrogen. Gainesville: University of Florida, 2000. p. A-25. (Bulletin, 339).

KABEYA, K. S.; PAULINO, M. F.; DETMANN, E.; VALADARES FILHO, S. C.; CECON, P. R.; QUEIROZ, D. S.; GOMES JÚNIOR, P. G.; PEREIRA, ${ }^{\circ} \mathrm{G}$. Suplementação de novilhos mestiços em pastejo na época de transição água-seca: Desempenho produtivo, características físicas de carcaça, consumo e parâmetros ruminais. Revista Brasileira de Zootecnia, Viçosa, MG, v. 31, n. 1, p. 213-222, 2002.

LICITRA, G.; HERNANDEZ, T. M.; VAN SOEST, P. J. Standardization of procedures for nitrogen fractionation of ruminant feeds. Animal Feed Science and Technology, Missouri, v. 57, n. 4, p. 347-358, 1996.

MATHIS, C. P.; COCHRAN, R. C.; HELDT, J. S.; WOODS, B. C.; ABDELGADIR, I. E.; OLSON, K. C.; TITGEMEYER, E. C.; VANZANT, E. S. Effects of supplemental degradable intake protein on utilization of medium- to low-quality forages. Journal of Animal Science, Champaign, v. 78, n. 1, p. 224-232, 2000.

MORAES, E. H. B. K.; PAULINO, M. F.; VALADARES FILHO, S. C.; MORAES, K. A. K.; DETMANN, E.; SOUZA, M. G. Avaliação nutricional de estratégias de suplementação para bovinos de corte durante a estação da seca. Revista Brasileira de Zootecnia, Viçosa, MG, v. 39, n. 3, p. 608-616, 2010.
MORAES, E. H. B. K.; PAULINO, M. F.; ZERVOUDAKIS, J. T.; VALADARES FILHO, S. C.; CABRAL, L. S.; DETMANN, E.; VALADARES, R. F. D.; MORAES, K. A. K. Associação de diferentes fontes energéticas e protéicas em suplementos múltiplos na recria de novilhos mestiços sob pastejo no período da seca. Revista Brasileira de Zootecnia, Viçosa, MG, v. 35, n. 3, p. 914-920, 2006.

NATIONAL RESEARCH COUNCIL - NRC. Nutrients requirements of dairy cattle. 7. ed. Washington, D. C.: National Academy Press, 2001. 381 p.

PAULINO, M. F.; FIGUEIREDO, D. M.; MORAES, E. H. B. K.; PORTO, M. O.; SALES, M. F. L.; ACEDO, T. S.; VILLELA, S. D. J.; VALADARES FILHO, S. C. Suplementação de bovinos em pastagens: uma visão sistêmica. In: SIMPÓSIO DE PRODUÇÃO DE GADO DE CORTE, 4., 2004, Viçosa, MG. Anais... Viçosa, MG: SIMCORTE, 2004. p. 93-144.

PORTO, M. O.; PAULINO, M. F.; VALADARES FILHO, S. C.; SALES, M. F. L.; LEÃO, M. I.; COUTO, V. R. M. Fontes suplementares de proteína para novilhos mestiços em recria em pastagens de capim-brachiaria no período das águas: desempenho produtivo e econômico. Revista Brasileira de Zootecnia, Viçosa, MG, v. 38, n. 8, p. 1553-1560, 2009.

REIS, R. A.; MELO, G. M. P.; BERTIPAGLIA, L. M. A.; OLIVEIRA, A. P. Otimização da utilização da forragem disponível através da suplementação estratégica. In: REIS, R. A.; SIQUEIRA, G. R.; BERTIPAGLIA, L. M. A.; OLIVEIRA, A. P.; MELO, G. M. P.; BERNARDES, T. F. (Ed.). Volumosos na produção de ruminantes. Jaboticabal: FUNEP, 2005. p. 187-238.

REIS, R. A.; RODRIGUES, L. R. A.; PEREIRA, J. R. A. A suplementação como estratégia do manejo de pastagem. In: SIMPÓSIO SOBRE MANEJO DA PASTAGEM, 13., 1997, Piracicaba. Anais ... Piracicaba: FEALQ, 1997. p. 123-150.

SILVA, D. J.; QUEIROZ, A. C. Análise de alimentos: métodos químicos e biológicos. 3. ed. Viçosa: Editora UFV, 2002. 235 p.

SILVA, F. F.; SÁ, J. F.; SCHIO, A. R.; ÍTAVO, L. C. V.; SILVA, R. R.; MATEUS, R. G. Suplementação a pasto: disponibilidade e qualidade $\mathrm{x}$ níveis de suplementação $\mathrm{x}$ desempenho. Revista Brasileira de Zootecnia, Viçosa, MG, v. 38, p. 371-389, 2009. Suplemento Especial.

SNEDECOR, G. W.; COCHRAN, W. G. Statistical methods. $8^{\text {th }}$ ed. Iowa: Iowa University Press, 1989. 503 p. 
SNIFFEN, C. J.; O'CONNOR, J. D.; VAN SOEST, P. J.; FOX, D. G.; RUSSELL, J. B. A net carbohydrate and protein system for evaluating cattle diets: II. Carbohydrate and protein availability. Journal of Animal Science, Cambridge, v. 70, n. 12, p. 3562-3577, 1992.

STATISTICAL ANALYSIS SYSTEM INSTITUTE - SAS. The statistical analyze systems for windows: version 9. 2. 2002-2008, Cary, NC: SAS Institute Inc., 2008.

VALADARES FILHO, S. C.; PAULINO, P. V. R.; MAGALHÃES, K. A. Exigências nutricionais de zebuínos e tabela de composição de alimentos. Viçosa: UFV, 2006. 142 p.
VALADARES FILHO, S. C.; PAULINO, P. V. R.; MAGALHÃES, K. A. Exigências nutricionais de zebuínos e tabelas de composição de alimentos (BRCORTE). Visconde do Rio Branco: Suprema Gráfica Ltda, 2006. v. 1, 142 p.

VILLELA, S. D. J.; PAULINO, M. F.; VALADARES FILHO, S. C.; MARTINS, M. O.; ZAMPERLINI, B. Fontes de proteína em suplementos para bovinos em pastejo nos períodos da seca e de transição secaáguas. Revista Brasileira de Saúde e Produção Animal, Salvador, v. 10, n. 2, p. 266-277, 2009. 
